\title{
Moderating Effects of Job Stress in Emotional Exhaustion and Feeling of Energy Relationships with Positive and Negative Behaviors: Job Stress Multiple Functions Approach
}

\author{
Mohsen Golparvar ${ }^{1}$, Manouchehr Kamkar ${ }^{2}$ \& Zahra Javadian $^{1}$ \\ ${ }^{1}$ College of Psychology and Education, Islamic Azad University, Khorasgan Branch, Esfahan, Iran \\ ${ }^{2}$ Department of Psychology, York University, Toronto, Canada \\ Correspondence: Mohesn Golparvar, College of Psychology and Education, Islamic Azad University, Khorasgan \\ Branch, Esfahan, 81551-39998, Iran. Tel: 98-913-329-6544. E-mail:drmgolparvar@gmail.com
}

Received: September 26, 2012

Accepted: November 5, 2012 Online Published: November 27, 2012

doi:10.5539/ijps.v4n4p99

URL: http://dx.doi.org/10.5539/ijps.v4n4p99

\begin{abstract}
The aim of the present study was to investigate the relationships between emotional exhaustion and feeling of energy with positive and negative behavioral outcomes at workplaces with consider moderating effects of job stress among employees of an industrial organization in Esfahan, Iran. Using a simple random sampling method, a sample of 275 employees completed the job stress, emotional exhaustion, feeling of energy, deviant behaviors, organizational citizenship behavior and creativity questionnaires. The results revealed that: 1) Job stress moderates the relationship between emotional exhaustion and deviant behaviors. That is, in low job stress, emotional exhaustion negatively and significantly related to deviant behaviors, while in high job stress, emotional exhaustion positively and significantly related to deviant behaviors. 2) Job stress also moderates the relationship between emotional exhaustion and organizational citizenship behaviors (OCBs). That is, in low job stress, emotional exhaustion positively and significantly related to organizational citizenship behaviors (OCBs).
\end{abstract}

Keywords: job stress, emotional exhaustion, feeling of energy, deviant behaviors, organizational citizenship behaviors, creativity

\section{Introduction}

Workplaces are environments where a variety of different behaviors of employees are expressed in, each with a different consequence to the individuals as well as the entire organization (Spector, 2006). In essence, employees' behaviors in workplaces which have different effects on organizational performance usually fall within two categories: positive and negative. Positive behaviors help organizations to achieve their goals. As an example of these behaviors, we can point to the organizational citizenship behaviors (OCBs) and creativity. Since they enhance organizational performance, these behaviors through creating suitable psycho-social environment, facilitate the work processes in organization. In contrast, negative behaviors threaten the organization through weakened individuals and organization well-being (Coccia, 1998; Galperin, 2002; Lawrence \& Robinson, 2007; Appelbaum, Iaconi \& Matousek, 2007). In recent two decades, many researchers focused on individuals and situational variables which influenced the employees' behaviors at workplaces. Congruent with above mentioned attention, in current research focused on emotional exhaustion, feelings of energy and job stress are as variables correlated to deviant behaviors (as negative behaviors), organizational citizenship behaviors (OCBs) and creativity (as positive behaviors).

\section{Conceptual Framework of Research Variables}

\subsection{Deviant Behaviors}

One of the very interesting categories of behaviors in workplaces is deviant behaviors (Appelbaum et al, 2007). Negative deviant workplace behavior includes behaviors such as absenteeism, withdrawal, withholding effort at work, sexual harassment, unethical decision making, not following the manager's instructions, intentionally slowing down the work cycle, arriving late to work, vandalism, rumor spreading and corporate sabotage (Robinson \& Bennett, 1995). Different researchers have given different names to negative deviant behaviors including workplace deviance (Bennett \& Robinson, 2003), counterproductive behavior, antisocial behavior 
(Giacolone \& Greenberg, 1997), destructive behaviors, retaliatory behaviors, and organizational incivility (Golparvar \& Karmi, 2010). Generally, deviant behavior is defined as an intentional employee behavior that is harmful to the legitimate interests of an organization (Skarlicki, Folger \& Tesluck, 1997; Bennett \& Robinson, 2000; Martinko, Gundlach, \& Douglas, 2002; Gruys \& Sackett, 2003; Sackett, Berry, Wiemann \& Laczo, 2006). Researchers recognized two categories of deviant behaviors, which are individually oriented deviant behaviors (e.g., acting rudely toward others) and organizationally oriented deviant behaviors (e.g., taking property without permission, intentionally doing low quality work and so on). Theoretically, deviance has often been recognized as a reaction to frustration/failure of organizational stressor factors such as financial, social, and working conditions. Some empirical studies revealed that increasing job stress and emotional exhaustion have resulted from work overload, role ambiguity, work conflict and job demands beyond skills and resources available to individuals lead to deviant behaviors (Sackett \& DeVore, 2001; Boyd, Lewin \& Sager, 2009).

\subsection{OCBs and Creativity}

Organizational citizenship behaviors (OCBs) and creativity are the two positive behavioral outcomes in current research. OCBs were defined as intentional employee behaviors that are discretionary and typically not recognized or rewarded, but improve the function of the organization (Organ, 1995; Spector, 2006). More recently, however, it has been acknowledged that OCBs may be recognized and rewarded during performance appraisals (Organ, 1995). After Organ's five-dimension model (altruism, courtesy, conscientiousness, civic virtue, and sportsmanship), many authors have defined different OCBs dimensions. For instance, Williams and Anderson (1991) and Van Scotter and Motowidlo (1996) described two different dimensions, one served as indicators of organizational citizenship behaviors toward individuals (OCB-I, altruism and courtesy) and another served as indicators of organizational citizenship behaviors toward organization (OCB-O, conscientiousness, civic virtue, and sportsmanship). Previous empirical research revealed that OCBs are related to job satisfaction, motivation, organizational justice, organizational performance, and organizational commitment (Spector, 2006; Bukhari \& Ali, 2009; Podsakoff, Whiting, Podsakoff \& Blume, 2009). Along with OCBs, employees' creativity at workplace is the foundation of any high-performance organization. As Amabile (1997) explains, creativity is the first step in innovation which is the successful implementation of that novel, appropriate ideas. There is a great deal of research on ways in which cognitive, affect, and work context can enable more creativity and innovative behavior (Ward, 2004). Empirical findings suggest that creativity is related to intelligence and wisdom, creative self-efficacy, unconscious thought processes, and openness to experience (Carmeli \& Schaubroeck, 2007; Darvish \& Farzane-dokht, 2011).

\subsection{Job Stress and Emotional Exhaustion}

Job stress is a condition or situation at work that requires an adaptive response on the part of the employee. Role ambiguity and role conflict are the most studied stressors in the job stress domain (Dowden \& Tellier, 2004; Lambert, Hogan \& Griffin, 2007; Ouyang, 2009). Existing empirical researches provide many findings show that job stress is associated with negative behaviors such as deviant and counterproductive behaviors (Lambert et al, 2007). Along with job stress, burnout can be defined as a state of physical, emotional, and mental exhaustion that results from long-term involvement in work situations that drain the employees emotionally (Golparvar, Nyeri \& Mahdad, 2009). In a similar vein, burnout can be conceptualized as a reaction to the negative psychological experience of job-related stress (Maslach \& Jackson, 1981). Thus, it can be concluded that burnout is not a symptom of work stress (Golparvar et al, 2009; Sesen, Cetin \& Basim, 2011). Therefore, if personal and organizational stress can be successfully managed, the incidence of burnout will be reduced. Maslach \& Jackson's (1981) model of burnout have three components. One of them is emotional exhaustion. Emotional exhaustion refers to feelings of being drained by tasks and duties at workplaces. It can be assumed that emotionally exhausted employees would feel more tired, expend less effort at work, and be unwilling to help others (Mulki, Jaramillo \& Locander, 2006).

\subsection{Feeling of Energy}

Feeling of energy includes a state of positive affect and tends to perform duties energetically (Quinn \& Dutton, 2005; Darvish \& Farzane-dokht, 2011). Within the work context, feeling of energy is a positive state that helps employees work effectively (Dutton, 2003). An employee with high feeling of energy contrast to an employee with feeling of fatigue feels alert, energized, and spirited (Spreitzer, Sutcliffe, Dutton, Sonenshein, \& Grant, 2005; McNair, Lorr, \& Droppleman, 1992; Watson \& Clark, 1994). Positive feelings increase readiness for performing and cause the increasing thought and immediate attention to an individual (Quinn, 2007; Atwater \& Carmeli, 2009). Positive energy is a form of influence/impact feeling that would reinforce the behavior people enjoys doing it. In contrary to it, feeling less energy causes a decrease in performance capabilities. Empirical evidence shows 
that people with experiences in high-level relationship possess more energy and more positive affectionate such as joy, interest and love. This shows that the individual at this moment has more performance and intellectual capacity. This will result in more effective capacity and tendency to exchange with others and provides conditions for expanding energy (Golparvar, Padash \& Atashpoor, 2010).

\subsection{Empirical and Theoretical Evidences about Linkage between Research Variables}

In the literature, some theories and models try to explain the basic mechanisms which relate job stress and emotional exhaustion to positive and negative behavioral outcomes at workplaces. Environmental events emotion - behavior model (Spector \& Fox, 2002) asserts that negative emotion (i.e., angry) facilitates deviant behaviors, whereas positive emotion (i.e., positive affect) tends to facilitate OCBs. In essence, on the basis of environmental events - emotion - behavior model (Spector \& Fox, 2002), continued exposure to emotion-arousing events will heighten the likelihood for a person to engage in behavioral response. On the basis of this model, job stress induces negative emotion, and then heightens the likelihood of deviant behaviors. O'Brien's (2008) stressor-strain model asserts that OCBs and deviant behaviors are first affected by organizational stressors, and then personality, particularly trait-oriented emotions and attributional styles, affect the perceived job stressors and strains at workplaces. Since burnout has significant effects on employee's job motivation and organizational achievement (O'Brien, 2008), we can expect that employees experiencing greater levels of burnout will exhibit less OCBs, and furthermore, it is likely that this decline in OCBs will result in more complex and difficult working conditions, lead to produce greater numbers of unsatisfied, unmotivated, and unhappy employees. Another model for explaining the fundamental mechanism about relationships between job stress and emotional exhaustion with positive and negative behavioral outcomes at workplaces is stress - non-equilibrium - compensation approach (Golparvar \& Hosseinzadeh, 2011).On the basis of this model, stress first induced non-equilibrium state in the human system, and then motivate them to strive to return the previous equilibrium. Some people for returning equilibrium, if simultaneously experience the negative emotions (e.g., emotional exhaustion), will become ready to engage in deviant behaviors. On the basis of this model, when job stress and emotional exhaustion are high, the likelihood of OCBs and creativity will decrease. In current research, among above mentioned theoretical models, we focused on stress - non-equilibrium - compensation approach.

There are some empirical studies that have demonstrated the relationships between job stress and emotional exhaustion with deviant behaviors, creativity and OCBs. Heacox (1996) found that there is significant relationship between employees' emotional frustration with supervisor's reports about employees' deviant behaviors. Cropanzano, Howes, Grandey, and Toth (1997) also found that deviant behaviors are related to high levels of job tension, somatic tension, fatigue, and burnout. Cropanzano, Rupp \& Byrne (2003) investigated the effects of emotional exhaustion on OCBs by treating OCBs in two dimensions as proposed by Williams and Anderson (1991). They found that emotional exhaustion had only affected OCBO negatively and had no effect on OCBI. In another study, Van Emmerik, Jawahar \& Stone (2005) studied associations between altruism, burnout and OCBs. They reported a negative relation between OCBs and reduced personal accomplishment and between altruism and emotional exhaustion (Van Emmerik et al, 2005). Dalal's (2005) meta- analytic review found that each of OCBs and deviant behaviors are significantly related to job stress and emotional states in different samples. In a study, Chiu and Tsai (2006) have also explored the relationship between burnout and OCBs. They measured OCBs in three categories including interpersonal citizenship performance, organizational citizenship performance, and task/job citizenship performance. They found negative correlations between OCBs, and emotional exhaustion and reduced personal accomplishment. Appelbaum et al (2007) reviewed some of theories and researches about correlates of positive and negative deviant behaviors and concluded that job stress and emotional exhaustion are stable correlates of these behaviors. O'Brien (2008) on the basis of the stressor-strain model realized that OCBs and deviant behaviors are affected by stressors, including interpersonal conflict, low interactional justice, job demands, and organizational constraints. Additionally, trait emotion and attributional styles affect the amount of perceived stressors.

Podsakoff et al (2009) in a meta- analysis indicated that OCBs are related to employees' performance, reward allocation decisions, turnover intentions, and absenteeism. In addition, OCBs were found to be related to productivity, efficiency, reduced costs, customer satisfaction, and unit-level turnover (Podsakoff et al, 2009). Also researches revealed that creative behavior requires much more time and energy (Amabile, 1998; Amabile, Barsade, Mueller \& Staw, 2003). Some of studies showed that creativity influenced by feeling of energy (Tierney, Farmer, \& Graen, 1999; Mumford, Scott, Gaddis, \& Strange, 2002; Atwater \& Carmeli, 2009). In essence, positive feeling experiences through reinforcing feeling of energy, lead to thinking and self-creating actions in individuals (Golparvar et al, 2010). In this domain, the prosperity model states that happiness expression cause increasing positive senses which rooted in individuals' relationships with other people. Interactions with other 
people lead to creating individual energy at work (George \& Zhou, 2001; Hunter, Bedell, \& Mumford, 2007; Atwater \& Carmeli, 2009; Golparvar et al, 2010).

Some of researches in an Iranian work context also showed that there is a negative significant relationship between job stress and emotional exhaustion with OCBs and creativity, and positive significant relationship between job stress and emotional exhaustion with deviant behaviors (Golparvar et al, 2009; Golparvar \& Vaseghi, 2011; Golparvar \& Hosseinzadeh, 2011). Golparvar et al (2009) revealed that job stress and emotional exhaustion negatively related to deviant behaviors toward the organization. In another study (Golparvar \& Vaseghi, 2011), It is found that feeling of energy negatively related to job stress and deviant behaviors, and positively related to creativity and organizational citizenship behaviors. The results of structure equation modeling revealed that feeling of energy played a complete mediator role in relations between job stress with deviant behaviors, organizational citizenship behaviors and creativity. Golparvar and Hosseinzadeh (2011) studied the relationship between person- job none fit (as a source of job stress) with emotional exhaustion and turnover, and found that person - job none fit positively related to intention to quit the organization.

\subsection{Practical Implications of Current Research}

As it could be seen, in many previous studies, it is evident that job stress introduced as predictor of emotional exhaustion, feeling of energy, deviant behaviors, OCBs and creativity (Spector \& Fox, 2002; O'Brien, 2008; Golparvar \& Vaseghi, 2011). In a review of the above mentioned research findings, some questions arise that have not been studied previously. One of the most important questions is that, although stress impacts on positive and negative behavioral outcomes at workplaces, but what will happen for employees' behavioral reactions when they are emotionally exhausted or energetic with increasing job stress?. We believe that, on the basis of replaceable variables approach and theoretical relativism (Golparvar \& Javadian \& Barazandeh, 2011) and stress non-equilibrium - compensation approach (Golparvar et al, 2009; Golparvar \& Vaseghi, 2011; Golparvar \& Hosseinzadeh, 2011), job stress as a factor which disturbs the psychological and behavioral equilibrium of employees (negative versus positive), when employees are exhausted or energetic, increasingly disturbs equilibrium of them, and changes their behavioral reactions to the situation. In other words, the underpinning perspective of this research on the basis of stress - non-equilibrium - compensation approach (Golparvar et al, 2009; Golparvar \& Vaseghi, 2011; Golparvar \& Hosseinzadeh, 2011), is that job stress as disturbing factor of equilibrium between positive -negative emotions changes the behavioral outcomes of emotional exhaustion and feeling of energy. In normal position it is assumed that there is a balance between negative and positive emotions of people. Therefore, it is rational to assume that job stress has moderating effects on the relationship between emotional exhaustion and feeling of energy with deviant behaviors, OCBs and creativity. Another underpinning perspective of this research is that job stress is a personal and situational variable which in context of emotional and affective variables (such as emotional exhaustion and feeling of energy) have different functions (multiple functions approach to job stress). However, rare are the studies that examine the moderating effects of job stress for emotion and behaviors linkage at workplaces. Concomitantly, few empirical studies examined the relationship between emotional exhaustion and feeling of energy with organizational citizenship behaviors (OCBs), and also creativity and deviant behaviors with considering the moderating effects of job stress. Our model suggests that a focus on moderating effects of job stress may be an effective way to address some employees' behavior reactions at workplaces. The conceptual model of research presented in figure 1. In this figure, emotional exhaustion and feeling of energy are the predictors of deviant behaviors, OCBs and creativity. Then deviant behaviors, OCBs and creativity are outcome (criterion) variables, and job stress is a moderating variable. 


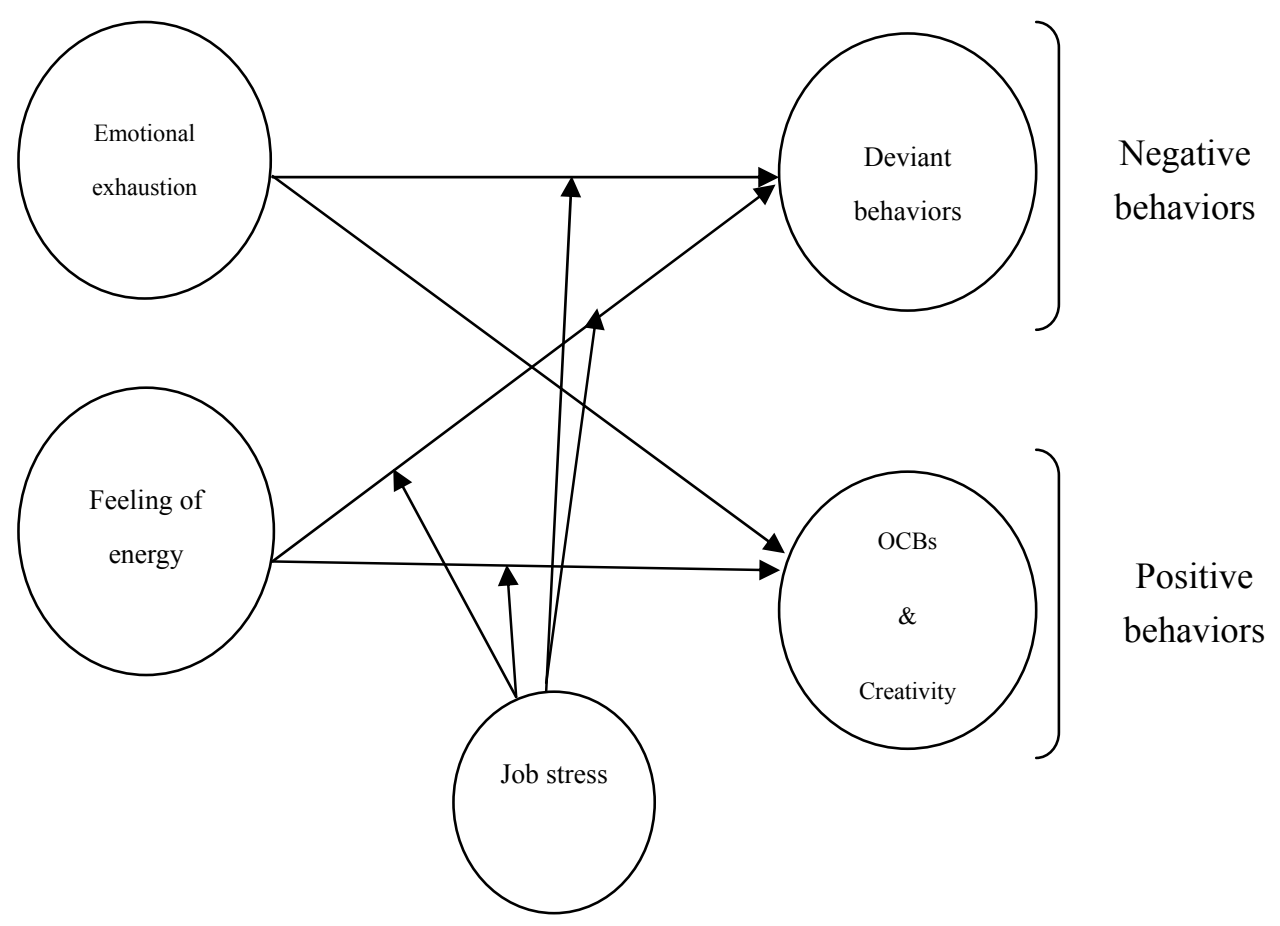

Figure. 1. Conceptual model of research

\section{Hypotheses}

H1: Job stress would moderate the relationship between emotional exhaustion and deviant behaviors; there is a different relationship between emotional exhaustion and deviant behaviors at low and high levels of job stress.

H2: Job stress would moderate the relationship between emotional exhaustion and organizational citizenship behaviors; there is a different relationship between emotional exhaustion and organizational citizenship behaviors at low and high levels of job stress.

H3: Job stress would moderate the relationship between emotional exhaustion and creativity; there is a different relationship between emotional exhaustion and creativity at low and high levels of job stress.

H4: Job stress would moderate the relationship between feeling of energy at work and deviant behaviors; there is a different relationship between feeling of energy at work and deviant behaviors at low and high levels of job stress.

H5: Job stress would moderate the relationship between feeling of energy at work and organizational citizenship behaviors; there is a different relationship between feeling of energy at work and organizational citizenship behaviors at low and high levels of job stress.

H6: Job stress would moderate the relationship between feeling of energy at work and creativity; there is a different relationship between feeling of energy at work and creativity at low and high levels of job stress.

\section{Method}

\subsection{Participants}

In the present investigation we have used a co-relational design. This design is suitable to explore the relationship between predictors, moderators and criterion variables. This investigation was conducted in two industrial organizations with the same productions in Esfahan, Iran. Among three hundreds distributed questionnaires, two hundreds and seventy five employees completed the questionnaires. The response rate was $91.67 \%$, which was very much acceptable in social sciences researches and in hierarchical moderated regression analysis (Cohen, Cohen, West \& Aiken, 2003). The $72.3 \%$ of the participants were males and $27.7 \%$ were 
females. $71.3 \%$ of them were married (196 respondent), and others were single (74 respondents or $28.7 \%$ ). $54.8 \%$ had secondary studies or diploma, and $46.2 \%$ had university studies, and $7.1 \%$ had management position and $92.9 \%$ had no management position. Finally, the mean age of the participants was $36.94(\mathrm{SD}=8.37)$, and the mean tenure of the participants was 13.72 years $(\mathrm{SD}=7.1)$. The mean experience of the participants in their current profession was 10.85 years $(\mathrm{SD}=6.75)$.

\subsection{Measures}

\subsubsection{Job Stress}

A short form of job stress scale (Golparvar \& Vaseghi, 2011) was chosen to assess the job stress of the sample. The questionnaire is consisted of 5 items (a sample item is: often my job duties make nervous me). Total score on this scale is considered for the assessment of job stress and more the score indicates more the stress. Respondents were asked to indicate whether an item was a source of stress on a 5-point scale with anchors, $5=$ strongly agree and $1=$ strongly disagree. The reliability and validity of the scale have been demonstrated in Iran (Golparvar \& Vaseghi, 2011). Cronbach's alpha of this scale in present investigation was 0.7.

\subsubsection{Deviant Behaviors}

Deviant behaviors were measured with using fifty items which adapted from Bennett and Robinson (2000). This scale has been translated and validated in Iranian work settings in the previous research (Golparvar and Vaseghi, 2011), and assessed deviant behaviors toward organization and toward individuals. Respondents were asked to indicate how often they engaged in activities such as staying home instead going to work and saying I was sick. Responses were rated on a 7-point scale, ranging from 1 (never) to 7 (often). Previous research suggested that the Iranian version of the deviant behaviors questionnaire had a good construct and concurrent validity (Golparvar \& Vaseghi, 2011).The internal consistency (Cronbach's alpha) of this questionnaire in present study was 0.92 .

\subsubsection{Organizational Citizenship Behaviors}

Organizational citizenship behaviors were measured by means of nine items adapted from Bukhari and Ali (2009). This questionnaire was translated and validated by Golparvar and Vaseghi (2011) in Iran. A sample item is: Helped others who have been absent. Responses were rated on a 7-point scale, ranging from 1 (never) to 7 (often).This questionnaire assessed organizational citizenship behavior toward organization and toward individuals simultaneously. Golparvar and Vaseghi (2011) have reported the construct validity (on the basis of exploratory factor analysis) and Cronbach's alpha $(\alpha=0.92)$ of this questionnaire. The internal consistency (Cronbach's alpha) of this questionnaire in present study was 0.8 .

\subsubsection{Creativity}

Creativity was assessed with nine items adapted from Tierney et al (1999). This questionnaire was translated and validated in Iranian workplaces in previous research (Golparvar et al, 2010). Respondents were asked to indicate how often they engaged in activities such as come up with creative solutions to problems, in7-point scale, ranging from 1 (never) to 7 (often). Golparvar et al (2010) have reported the construct validity (on the basis of exploratory factor analysis) and Cronbach's alpha $(\alpha=0.87)$ of this questionnaire. The internal consistency (Cronbach's alpha) of this questionnaire in present study was 0.88 .

\subsubsection{Emotional Exhaustion}

The subscale of emotional exhaustion from Maslach Burnout Inventory with nine items which adapted from Mulki et al (2006) was used for assessment of emotional exhaustion. Golparvar et al (2009) translated and validated this scale in Iran. A sample item is: I feel emotionally drained from my work. Golparvar et al (2009) have reported the construct validity (on the basis of exploratory factor analysis) and Cronbach's alpha $(\alpha=0.91)$ of this questionnaire. The internal consistency (Cronbach's alpha) of this questionnaire in present study was 0.76 .

\subsubsection{Feeling of Energy at Work}

Feeling of energy at work was assessed with nine items adapted from Atwater and Carmeli (2009). Golparvar et al (2010) translated and validated this questionnaire in Iran. Total score on this scale is considered for the assessment of feeling of energy and more the score indicates more the feeling of energy. A sample item of this questionnaire is: I am energetic when perform my work task (Golparvar et al, 2010). Cronbach's alpha of this scale in present study was 0.88 . 


\section{Results}

Data were analyzed with using SPSS17 (Statistical Package for Social Science) to compute correlations, descriptive results and performing hierarchical moderated regression analysis. Box plot revealed that outlier and extreme values are not problematic in present investigation. Out of the total responses, missing values were less than 0.5 percent, which replaced with the mean of variables in database. To prevent problems of multicollineality, hierarchical moderated regression analysis were conducted with the centered variables (Aiken \& West, 1991; Cohen, Cohen, West, \& Aiken, 2003). Inter-correlations, means and standard deviations for all variables are reported in Table 1.

Table 1. Mean, standard deviation and inter-correlations for study variables

\begin{tabular}{lllllllll}
\hline & $\mathrm{M}$ & $\mathrm{SD}$ & 1 & 2 & 3 & 4 & 5 & 6 \\
\hline job stress & 3.36 & 1.11 & 0.7 & & & & & \\
emotional exhaustion & 3.32 & 1.02 & $0.7^{* *}$ & 0.76 & & & & \\
feeling of energy & 4.69 & 1.26 & $-0.59^{* * *}$ & $-0.6^{* *}$ & 0.88 & & & \\
deviant behaviors & 2.44 & 1.17 & $0.38^{* *}$ & $0.48^{* *}$ & $-0.48^{* *}$ & 0.92 & & \\
organizational citizenship behavior & 5.07 & 1.09 & $-0.34^{* *}$ & $-0.33^{* *}$ & $0.56^{* *}$ & $-0.68^{* *}$ & 0.8 & \\
creativity & 4.56 & 1.01 & $-0.29^{* *}$ & $-0.32^{* *}$ & $0.56^{* *}$ & $-0.48^{* *}$ & $0.67^{* *}$ & 0.88 \\
\hline
\end{tabular}

Note. ${ }^{* *} \mathrm{p}<0.01$, Internal consistency reliabilities are reported on the diagonal.

As shown in Table 1, all correlations among the research measures were statistically significant $(\mathrm{p}<0.01)$. Job stress related positively to deviant behaviors $(r=0.38, p<0.01)$, and negatively related to feeling of energy $(r=-$ $0.59, \mathrm{p}<0.01)$, to organizational citizenship behaviors $(\mathrm{r}=-0.34, \mathrm{p}<0.01)$ and to creativity $(\mathrm{r}=-0.29, \mathrm{p}<0.01)$. Emotional exhaustion related positively to deviant behaviors $(\mathrm{r}=0.48, \mathrm{p}<0.01)$, and related negatively to feeling of energy $(r=-0.6, p<0.01)$, to organizational citizenship behaviors $(r=-0.33, p<0.01)$ and to creativity $(r=-0.32, p<0.01)$. Feeling of energy related positively to organizational citizenship behaviors $(r=-0.56$, $\mathrm{p}<0.01)$ and to creativity $(\mathrm{r}=-0.56, \mathrm{p}<0.01)$, and related negatively to deviant behaviors $(\mathrm{r}=0.48, \mathrm{p}<0.01)$. Deviant behaviors related negatively to organizational citizenship behaviors $(r=-0.68, p<0.01)$ and to creativity $(\mathrm{r}=-0.43, \mathrm{p}<0.01)$. Finally, creativity related positively to organizational citizenship behaviors $(\mathrm{r}=0.67, \mathrm{p}<$ 0.01). Moderated hierarchical regression analysis was used to test the moderating effect of job stress in relationships between emotional exhaustion and feeling of energy with positive and negative behavioral outcomes. Table 2 presents the result of the hierarchical moderated regression analysis.

Table 2. Hierarchical moderated regression analysis of job stress, emotional exhaustion and feeling of energy on positive and negative behavioral outcomes

\begin{tabular}{llllllllll}
\hline & \multicolumn{3}{l}{ Deviant behavior } & \multicolumn{3}{l}{ OCBs } & \multicolumn{3}{l}{ Creativity } \\
\cline { 2 - 10 } & Model 1 & Model 2 & Model 3 & Model 1 & Model 2 & Model 3 & Model 1 & Model 2 & Model 3 \\
& $\beta$ & $\beta$ & $\beta$ & $\beta$ & $\beta$ & $\beta$ & $\beta$ & $\beta$ & $\beta$ \\
\hline Feeling of Energy (FOE) & $-0.29^{* *}$ & $-0.3^{* *}$ & $-0.25^{* *}$ & $0.56^{* *}$ & $0.55^{* *}$ & $0.53^{* *}$ & $0.58^{* *}$ & $0.59^{* *}$ & $0.6^{* *}$ \\
Emotional Exhaustion (EE) & $0.29^{* *}$ & $0.3^{* *}$ & $0.27^{* *}$ & 0.003 & 0.02 & -0.01 & 0.02 & -0.02 & -0.02 \\
Job Stress (JS) & - & -0.01 & -0.06 & - & -0.03 & 0.01 & - & $0.07^{*}$ & $0.1^{*}$ \\
FOE $\times$ JS & - & - & 0.03 & - & - & -0.07 & - & - & -0.09 \\
EE $\times$ JS & - & - & $-0.24^{* *}$ & - & - & $0.12^{*}$ & - & - & 0.02 \\
$\mathrm{R}^{2}$ or $\Delta \mathrm{R}^{2}$ & $0.3^{* *}$ & 0 & $0.07^{* *}$ & $0.31^{* *}$ & 0.00 & $0.03^{* *}$ & $0.32^{* *}$ & 0.002 & $0.01^{*}$ \\
$\mathrm{~F}$ or $\Delta \mathrm{F}$ & $45.02^{* *}$ & 0.02 & $14.14^{* *}$ & $62.12^{* *}$ & 0.22 & $6.48^{* *}$ & $63.77^{* *}$ & 0.84 & $3.46^{*}$ \\
\hline
\end{tabular}

Note. ${ }^{*} \mathrm{P}<0.05 * * \mathrm{p}<0.01$, Model $1=$ main effects of feeling of energy (FOE) and emotional exhaustion (EE), Model 2 = main effect of job stress, and Model3 = interactive effects of feeling of energy (FOE), emotional exhaustion (EE) and job stress (JS). 
In Table 2, a three-stage hierarchical moderated regression analysis was used to test the research hypothesis about the moderating effects of job stress (JS) for deviant behavior, organizational citizenship behaviors (OCBs) and creativity. In Model 1, feeling of energy (FOE) and emotional exhaustion (EE) were entered as predictors of deviant behavior, organizational citizenship behaviors (OCBs) and creativity. In Model 2, the job stress (JS) was entered as a predictor of deviant behavior, organizational citizenship behaviors (OCBs) and creativity with feeling of energy (FOE) and emotional exhaustion (EE). In Model 3, the multiplicative interaction terms were entered. That is, the two-way, cross-product terms between feeling of energy (FOE) and emotional exhaustion (EE) with job stress (JS) were entered as predictors of deviant behavior, organizational citizenship behaviors (OCBs) and creativity. According to Aiken and West's (1991) recommendation for moderated regression analysis with multiplicative interaction terms, all the variables centralized and then entered in the regression equation. The moderator hypotheses (fourth hypothesis) were tested by examining the significance of the interaction teams and the F-tests associated with the changes in the multiple squared correlation coefficients $\left(\Delta R^{2}\right)$ of the equations in the Model 3.

The results indicated that, both of feeling of energy $(\beta=-0.29,-0.3$ and -0.25 for model 1 to $3, p<0.01)$ and emotional exhaustion $(\beta=0.29,0.3$ and 0.27 for model 1 to $3 p<0.01)$ influences significantly deviant behaviors, but only feeling of energy influences significantly organizational citizenship behaviors $(\beta=0.56,0.55$ and 0.53 for model 1 to $3, p<0.01)$ and creativity $(\beta=0.58,0.59$ and 0.6 for model 1 to $3, p<0.01)$. Job stress has no effects on deviant behaviors, organizational citizenship behaviors (OCBs) and creativity. But the emotional exhaustion $\times$ job stress term, explained a significant incremental portion of variance for deviant behaviors $(\Delta \mathrm{R} 2=$ $0.25, \mathrm{p}<0.01)$, and organizational citizenship behaviors $(\Delta \mathrm{R} 2=0.03, \mathrm{p}<0.01)$. To identify the form of the interaction, the equation at the high and low level of job stress was computed. Following the method described by Aiken and West (1991), equations predicting deviant behaviors and organizational citizenship behaviors (OCBs) from emotional exhaustion were derived for low and high levels of job stress (one standard deviation above the mean or $+1 \mathrm{SD}$, and one standard deviation below the mean or $-1 \mathrm{SD}$ ). Table 3 present the result of this regression analysis for prediction of deviant behaviors and organizational citizenship behaviors (OCBs) through emotional exhaustion at high and low levels of job stress.

Table 3. Results of regression analysis at high and low levels of job stress

\begin{tabular}{lllll}
\hline & \multicolumn{2}{l}{ deviant behaviors } & OCBs & \\
\cline { 2 - 5 } & Low job stress & High job stress & Low job stress & High job stress \\
\hline emotional exhaustion & $0.19^{*}$ & $-0.19^{*}$ & -0.14 & $0.25^{* *}$ \\
\hline
\end{tabular}

Note. $* \mathrm{P}<0.05 * * \mathrm{p}<0.01$; standardized beta are shown in table.

As can be seen in table 3, in low job stress, there is positive significant relationship between emotional exhaustion with deviant behaviors $(\mathrm{r}=0.19, \mathrm{p}<0.05)$, but in high job stress this relationship is significantly negative $(r=-0.19, p<0.05)$. Simple slope analysis presented in figure 2 . As shown in figure 2, emotional exhaustion related positively to deviant behaviors at low level of job stress, but related negatively to deviant behaviors at high level of job stress. Hypothesis 1 predicted that the relationship between emotional exhaustion with deviant behaviors would be different at low and high levels of job stress. The presented results in table 2 and 3 , and figure 2, providing support for $\mathrm{H} 1$.

Also as can be seen in table 3, in low job stress, there is no significant relationship between emotional exhaustion and organizational citizenship behaviors $(r=-0.19, p>0.05)$, but in high job stress, there is positive significant relationship between emotional exhaustion and organizational citizenship behaviors $(r=0.25, p<0.01)$. Simple slope analysis presented in figure 3. As shown in figure 3, emotional exhaustion related negatively to organizational citizenship behaviors at low level of job stress, but related positively to organizational citizenship behaviors at high level of job stress. Hypothesis 2 predicted that the relationship between emotional exhaustion with organizational citizenship behaviors would be different at low and high levels of job stress. The presented results in table 2 and 3, and figure 3, providing support for $\mathrm{H} 2$. Other hypotheses of current research (i.e., $\mathrm{H} 3, \mathrm{H} 4$, $\mathrm{H} 5$ and H6) have not been supported on the basis of the results (table 2 and 3). 


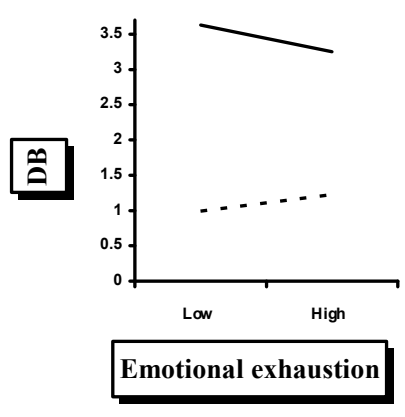

Figure 2. Interaction of emotional exhaustion (EE) and job stress (JS) for deviant behaviors (DB)

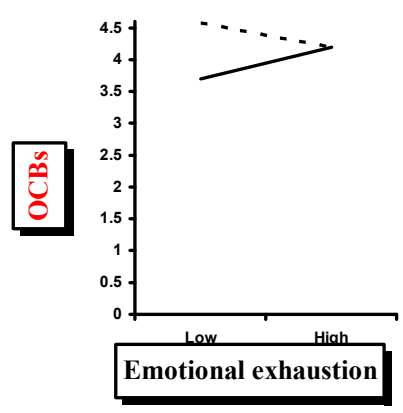

Figure 3. Interaction of emotional exhaustion (EE) and job stress (JS) for organizational citizenship behaviors (OCBs)

\section{Discussion}

The aim of this study was to explore the effects of job stress on the linkage between emotional and affective states (emotional exhaustion and feeling of energy at work) with negative and positive behavioral outcomes at workplaces. In zero-order correlations (table1), the results showed that employees who are more under job stress may be more emotionally exhaust with their job and may engage in deviant behaviors. In contrary, findings revealed that employees who are more under job stress and emotional exhaustion are less likely to engage in OCBs and creativity: but employees who have feeling of energy are less likely to engage in deviant behaviors and mutually they more likely tend to engaging in OCBs and creativity. A growing body of empirical evidences reported the relationships obtained in this research. Job stress has emerged as an important construct in industrial/ organizational psychology literature. In many researches it is revealed that positive relationship between job stress and deviant behaviors (i.e., Dalal, 2005; Appelbaum et al, 2007), and conversely negative relationship between job stress and organizational citizenship behaviors (Podsakoff et al, 2009). In addition, to better explaining the relationship between job stress with positive and negative behaviors, many researchers proposed models in which job stress with creating negative emotions and emotional exhaustion influenced positive and negative behaviors (Specter and Fox, 2002; O’Brien, 2008; Golparvar et al, 2009; Golparvar \& Vaseghi, 2011; Golparvar \& Hosseinzadeh, 2011). Although above mentioned findings have important implications for research and practice, but on the basis of stress - non-equilibrium - compensation approach, job stress as a factor which disturbed the psychological and behavioral equilibrium (negative versus positive), especially when employees feel exhausted, increasingly disturbs their equilibrium and subsequently creates a tendency to engaging in deviant behaviors and conversely it inhibits them to engage in organizational citizenship behaviors (Golparvar et al, 2009; Golparvar \& Hosseinzadeh, 2011).

Unlike previous studies, the current study tested the moderating effects of job stress on relationships between emotional exhaustion and feeling of energy at work with deviant behaviors, OCBs and creativity. Our findings relatively supported this assertion that individuals are experiencing high levels of job stress with increasing emotional exhaustion are less likely to exhibit deviant behaviors and more likely to exhibit OCBs. In fact, this study partially confirmed that job stress as a potential moderator variable which has different effects on 
employees' behaviors. More specifically, we believe that, effects of job stress on employees' behaviors are an emotional and affective related phenomenon. It seems that a pattern of job stress effects on employees' behaviors may also depend on the level of their perceived emotional exhaustion or conversely feeling of energy. Of most interest is the finding that when job stress is low, increase in emotional exhaustion increases deviant behaviors and conversely decreases organizational citizenship behaviors (OCBs). But when job stress is high, increase in emotional exhaustion decreases deviant behaviors and conversely increases organizational citizenship behaviors (OCBs). This trend of events has some explanations: perhaps when employees experience perceived emotional exhaustion, and simultaneously experience low job stress with perform deviant behaviors (and not performing organizational citizenship behaviors), should try to diminish their perceived emotional exhaustion. But when job stress is high, with performing organizational citizenship behaviors (and not performing deviant behaviors), employees try to access the organization or maybe coworkers support for better managing their perceived emotional exhaustion. To understand this finding, it might be informative to conceptualize the job stress as a multifunction phenomenon. The first function, in normal positions (i.e., when employees emotional exhaustion is low), is deviant behaviors increases and decreases of organizational citizenship behaviors (OCBs). But second function appears when emotional exhaustion increases. That is, with increasing perceived emotional exhaustion, the job stress decreases deviant behaviors and increases organizational citizenship behaviors (OCBs). If additional research in future supports our result that job stress moderates the relationship between emotional exhaustion with employees negative and positive behaviors, theoretically it would need to introduce and examine the multifunction of stress approach for clarifying the body of knowledge about human behaviors at workplaces.

On the basis of our knowledge there is no research addressing the moderating role of job stress and because of that this role at this time is based on speculation and needs further investigation in future. The results of the current research added the growing body of research on job stress and behavioral outcomes at workplaces in several ways. First, research on job stress tended to consider the main effects of this variable at the individual level and organizationally related criterions (such behaviors as deviant, citizenship and creativity) and has rarely considered the moderating role of this construct for the relationships between other related variables (such as emotional exhaustion) with negative and positive behavioral outcomes. Actually those relations between employee's attitudes and perception with behavioral outcomes do not occur in a vacuum, but in a context of related phenomenon at multiple levels. This study represents a first step in beginning to consider moderating effect of job stress to observed relationships. Afterwards, this study provides replication and extension of previous work linking emotional exhaustion with both organizational citizenship and deviant behaviors (e.g., Golparvar et al, 2009, 2010 and 2011) by showing that the relationship between these constructs can be dependent on individual level of job stress. Additionally, this research adds to research on deviant behaviors and organizational citizenship behaviors (OCBs) by linking the research domains of stress psychology and these organizationally oriented individual level behaviors. Moreover, the current research recalls job stress researchers to examine the extent as well as the mechanisms (which named job stress multiple functions approach) through which emotional exhaustion influenced positive and negative behavioral outcomes at workplaces. Having examined the job stress multiple functions approach, perhaps we can now better consider a role that job stress plays in individual and organizational performance and effectiveness. By examining the job stress as a moderator of the relationship between person's emotional exhaustion and, the amount of deviant behaviors and organizational citizenship behaviors (OCBs) demonstrated by that person, we can better help organizations and individuals for improving performance.

\section{Limitations and Research Implications}

Our study has some limitations as well. This research is only limited in an industrial organization in Esfahan, Iran and its conclusions may not be applicable to all organizations in Iran. We also suggest future researchers to select a bigger sample size (this may increase the clarification of moderating effect of job stress on relationship between feeling of energy and emotional exhaustion with positive and negative behavioral outcomes at workplaces) or choose employees of other administrative and service organizations as the objective and further testify the external validity of job stress multiple functions approach. Additionally, it is interesting to investigate other criterion variables such as contextual performance, task performance and turnover for extension of job stress multiple functions approach. Finally, the multiple function approach introduced in the present study should be expanded to include additional variables that are likely to influence the moderating effects of job stress on emotion-behavior outcomes linkages.

Although the problem of job stress is impossible to be eliminated entirely from workplaces, organizations still need to endeavor to deal with employees' job stress and emotional exhaustion and help them how to properly manage job stress and related outcomes. The findings of current research highlight the increasing importance of monitoring and addressing the job stress and emotional exhaustion on behavioral health of employees. The 
organizations should encourage or ask their employees to take a vacation after completing a difficult task. Furthermore, organizations should offer some psychology workshops or counseling courses which can release work- related stress. Training classes may also enhance the employee's skills for managing their job stress and emotional exhaustion in better and effective ways. The results of this study suggests that decreases in emotional exhaustion and job stress may have a suppressing effect on deviant behaviors and enhancing effect on organizational citizenship behaviors (OCBs). The respondents were asked whether they were engaged at deviant behaviors, OCBs or creativity. This is a rather general question and perhaps when this question is split up into different types of each of these construct (e.g., theft, harassment, and so on for deviant behaviors, or altruism, courtesy, sportsmanship, and so on for OCBs), a more detailed picture would emerge (Spector \& Fox, 2002).

\section{References}

Aiken, L. S., \& West, S. G. (1991). Multiple regression: Testing and interpreting interactions. New Bury Park, CA: SAGE.

Amabile, T. M. (1997). Motivating creativity in organizations: On doing what you love and loving what you do. California Management Review, 40(1), 39-58. http://dx.doi.org/10.2307/41165921

Amabile, T. M. (1998). How to kill creativity. Harvard Business Review, 76, 77-87.

Amabile, T. M., Barsade, S. G., Mueller, J. S., \& Staw, B. M. (2003). Affect and creativity at work: a daily longitudinal test. Working paper 03-071, Division of Research, Harvard Business School, Boston, MA.

Appelbaum, S. H., Iaconi, G. D., \& Matousek, A. (2007). Positive and negative deviant workplace behaviors: causes, impacts, and solutions. Corporate Governance, 7(5), 586-598. http://dx.doi.org/10.1108/14720700710827176

Atwater, L., \& Carmeli, A. (2009). Leader-member exchange, feeling of energy, and involvement in creative work. The Leadership Quarterly, 20, 264-275. http://dx.doi.org/10.1016/j.leaqua.2007.07.009

Bennett, R. J., \& Robinson, S. L. (2000). Development of a measure of workplace deviance. Journal of Applied Psychology, 85, 349-360. http://dx.doi.org/10.1037/0021-9010.85.3.349

Bennett, R. J., \& Robinson, S. L. (2003). The past, present and future of workplace deviance research', In Greenberg, J. (Ed.), Organizational behavior (pp. 247-81, 2nd ed). The State of the Science, Erlbaum,Mahwah, NJ.

Boyd, N. G., Lewin, J. E., \& Sager, J. K. (2009). A model of stress and coping and their influence on individual and organizational outcomes. Journal of Vocational Behavior, 75, 197-211. http://dx.doi. org/10.1016/j.jvb.2009.03.010

Bukhari, Z. U., \& Ali, U. (2009). Relationship between organizational citizenship behavior and counterproductive work behavior in the geographical context of Pakistan. International Journal of Business and Management, 4(1), 85-92.

Carmeli, A., \& Schaubroeck, J. (2007). The influence of leaders' and other referents' normative expectations on individual involvement in creative work. The Leadership Quarterly, 18, 35-48. http://dx.doi.org/10.1016/j.leaqua.2006.11.001

Chiu, S. F., \& Tsai, C. (2006). Relationships among burnout, job involvement, and organizational citizenship behavior. The Journal of Psychology, 140(6), 517-530. http://dx.doi.org/10.3200/JRLP.140.6.517-530

Coccia, C. (1998). Avoiding a toxic organization. Nursing Management, 29(5), 4-32. http://dx.doi.org/10.1097/00006247-199805000-00008

Cohen, J., Cohen, P. West, S. G., \& Aiken, L. S. (2003). Applied multiple regression/correlation analysis for the behavioral sciences (3rd ed). Mahwah, New Jersey, Lawrence Erlbaum Associations.

Cropanzano, R., Howes, J. C., Grandey, A. A., \& Toth, P. (1997). The relationship of organizational politics and support to work behaviors, attitudes, and stress. Journal of Organizational Behavior, 18, 159-180. http://dx. doi. 10.1002/(SICI)1099-1379(199703)18:2

Cropanzano, R., Rupp, D. E., \& Byrne, Z. S. (2003). The relationship of emotional exhaustion to work attitudes, job performance, and organizational citizenship behaviors. Journal of Applied Psychology, 88, 160-169. http://dx.doi.org/10.1037/0021-9010.88.1.160

Dalal, R. S. (2005). A meta-analysis of the relationship between organizational citizenship behavior and counterproductive work behavior. Journal of Applied Psychology, 90, 1241-1255. 
http://dx.doi.org/10.1037/0021-9010.90.6.1241

Darvish, H., \& Farzane-dokht, N. (2011). Studying the effect of leader member exchange in creating energy and creativity at workplace: a case study at Alzahra University. International Journal of Academic Research, $3(2), 1252-1259$.

Dowden, C., \& Tellier, C. (2004). Predicting work-related stress in correctional officers: A meta-analysis. Journal of Criminal Justice, 32, 31-47. http://dx.doi.org/10.1016/j.jcrimjus.2003.10.003

Dutton, J. E. (2003). Energize your workplace: How to build and sustain high-quality connections at work. San Francisco: Jossey-Bass Publishers.

Galperin, B. L. (2002). Determinants of deviance in the workplace: An empirical examination of Canada and Mexico. Unpublished doctoral dissertation. Concordia University, Montreal, Canada.

George, J. M., \& Zhou, J. (2001). When openness to experience and conscientiousness are related to creative behavior: An interactional approach. Journal of Applied Psychology, 86(3), 513-524. http://dx.doi.org/10.1037/0021-9010.86.3.513

Giacolone, R. A., \& Greenberg, J. (1997). Antisocial behavior in organizations. Sage Publishing, Thousand Oaks, CA.

Golparvar, M., \& Hosseinzadeh, K. H. (2011). Model of relation between person - job none fit with emotional exhaustion and desire to leave work: Evidence for the stress - un equilibrium - compensation model. Quarterly Journal of Applied Psychology, 20, 5(1/17), 41-56.

Golparvar, M., Javadian, Z., \& Brazandeh, A. (2011). The models of relationships between psychological contract with organizational commitment and job satisfaction: Replaceable variables and theoretical relativism. Journal of Psychological Models and Approaches, 1(3), 49-62.

Golparvar, M., \& Karami, M. (2010). Moderating role of positive and negative affect in relation to organizational injustice and employee's destructive behaviors. Quarterly Journal of Applied Psychology, 4(3), 7-23.

Golparvar, M., Nayeri, S., \& Mahdad, A. (2009). The relationship between stress, emotional exhaustion and organizational deviant behavior in Zoob Ahan Stock Company :Evidences for model of stress - exhaustion (none equilibrium)-compensation. Journal of New Findings in Psychology, 1(8), 19-34.

Golparvar, M., Padash, F., \& Atashpoor, H. (2010). Reinforcing model of feeling of energy, empowerment and employees creativity through ethical leadership. Iran Occupational Health, 7(3), 4-11.

Golparvar, M., \& Vaseghi, Z. (2011). Mediating role of energy at work in connection between stress with creativity, organizational citizenship behaviors and deviant behaviors. Journal of Psychological Models and Approaches, 1(3), 1-15.

Gruys, M. L., \& Sackett, P. R. (2003). Investigating the dimensionality of counterproductive work behavior. International Journal of Selection and Assessment, 11, 30-42. http://dx.doi.org/10.1111/1468-2389.00224

Heacox, N. J. (1996). The relationship between organizational frustration and aggressive behaviors in the workplace. Unpublished doctoral dissertation, California School of Professional Psychology, San Diego.

Hunter, S. T., Bedell, K. E., \& Mumford, M. D. (2007). Climate for creativity: A quantitative review. Creativity Research Journal, 19, 69-90. http://dx.doi.org/10.1080/10400410709336883

Lambert, E. G., Hogan, N. L., \& Griffin, M. L. (2007). The impact of distributive and procedural justice on correctional staff job stress, job satisfaction, and organizational commitment. Journal of Criminal Justice, 35, 644-656. http://dx.doi.org/10.1016/j.jcrimjus.2007.09.001

Lawrence, T. B., \& Robinson, S. L. (2007). Ain’t misbehaving: workplace deviance as organizational resistance. Journal of Management, 33(3), 378-394. http://dx.doi.org/10.1177/0149206307300816

McNair D. M., Lorr M., \& Droppleman L. F. (1992). Manual for the Profile of Mood States. San Diego, CA: Educational and Industrial Testing Service.

Martinko, M. J., Gundlach, M. J., \& Douglas, S. C. (2002). Toward an integrative theory of counterproductive workplace behavior: A causal reasoning perspective. International Journal of Selection and Assessment, 10, 36-50. http://dx.doi.org/10.1111/1468-2389.00192

Maslach, C., \& Jackson, S. E. (1981). The measurement of experienced burnout. Journal of Occupational Behavior, 2, 99-113. http://dx.doi.org/10.1002/job.4030020205 
Mulki, J. P., Jaramillo, F., \& Locander, W. B. (2006). Emotional exhaustion and organizational deviance: can the right job and a leader's style make a difference? Journal of Business Research, 59, 1222-1230. http://dx.doi.org/10.1016/j.jbusres.2006.09.001

Mumford, M. D., Scott, G. M., Gaddis, B., \& Strange, J. M. (2002). Leading creative people: orchestrating $\begin{array}{llll}\text { expertise and } \text { relationships. Leadership } & \text { Quarterly, 13, }\end{array}$ http://dx.doi.org/10.1016/S1048-9843(02)00158-3

O'Brien, K. E. (2008). A stressor-strain model of organizational citizenship behavior and counterproductive work behavior. Theses and Dissertations. Paper 432. Retrieved from http://scholarcommons.usf.edu/etd/432

Organ, D.W. (1995). Personality and organizational citizenship behavior. Journal of Management, 20, 465-478. http://dx. doi.10.1177/014920639402000208.

Ouyang, Y. (2009). The mediating effects of job stress and job involvement under job instability: Banking service personnel of Taiwan as an example. Journal of Money, Investment and Banking, 11, 16-26. Retrieved from http://www.eurojournals.com/JMIB.htm

Podsakoff, N. P., Whiting, S. W., Podsakoff, P. M., \& Blume, B. D. (2009). Individual- and organizational-level consequences of organizational citizenship behaviors: A meta-analysis. Journal of Applied Psychology, 94(1), 122-141. http://dx.doi.org/10.1037/a0013079

Quinn, R. W. (2007). Energizing others in work relationships. In J. E. Dutton \& B. R. Ragins (Eds.), Exploring positive relationships at work: Building a theoretical and research foundation (pp. 73-90). New York: Routledge.

Quinn, R. W., \& Dutton, J. E. (2005). Coordination as energy-in-conversation. Academy of Management Journal, 30(1), 36-57. http://dx.doi.org/10.5465/AMR.2005.15281422

Robinson, S. L., \& Bennett, R. J. (1995). A typology of deviant workplace behaviors: a multidimensional scaling study. Academy of Management Journal, 38, 555-572. http://dx.doi.org/10.2307/256693

Sackett, P. R., Berry, C. M., Wiemann, S. A., \& Laczo, R. M.(2006). Citizenship and counterproductive behavior: clarifying relations between the two domains. Human Performance, 19(4), 441-464. http://dx.doi.org/10.1207/s15327043hup1904_7

Sackett, P. R., \& DeVore, C. J. (2001). Counterproductive behaviors at work. In N. Anderson, D. Ones, H. Sinangil, \& C. Viswesvaran (Eds.), International handbook of work psychology. London: Sage.

Sesen, H., Cetin,C., \& Basim, H. N. (2011). The effect of burnout on organizational citizenship behavior: The mediating role of job satisfaction. International Journal of Contemporary Economics and Administrative Sciences, 1(1), 40-64.

Skarlicki, D. P., Folger, R., \& Tesluck, P. (1997). Personality as a moderator in the relationship between fairness and retaliation. Academy of Management Journal, 42, 100-108. http://dx.doi.org/10.2307/256877

Spector, P. E. (2006). Industrial and organizational psychology: research and practice. John Wiley \& Sons, Inc. NJ.

Spector, P. E., \& Fox, S. (2002). An emotion-centered model of voluntary work behavior: Some parallels between counterproductive work behavior and organizational citizenship behavior. Human Resource Management Review, 12, 269-292. http://dx.doi.org/10.1016/S1053-4822(02)00049-9

Spreitzer, G., Sutcliffe, K., Dutton, J., Sonenshein, S., \& Grant, A. M. (2005). A socially embedded model of thriving at work. Special Issue: Frontiers of organization science, Part 2 of 2, 16, 537-549.

Tierney, P., Farmer, S. M., \& Graen, G. B. (1999). An examination of leadership and employee creativity: The relevance of traits and relationship. Personnel Psychology, 52(3), 591-620. http://dx.doi.org/10.1111/j.1744-6570.1999.tb00173.x

Van Emmerik, H., Jawahar, I. M., \& Stone, T. H. (2005). Associations among altruism, burnout dimensions, and $\begin{array}{lllll}\text { organizational citizenship behavior. Work \& } & \text { Stress, } & \text { 19(1), } & \text { 93-100. }\end{array}$ http://dx.doi.org/10.1080/02678370500046283

Van Scotter, J. R., \& Motowidlo, S. J. (1996). Interpersonal facilitation and job dedication as separate facets of contextual performance. Journal of Applied Psychology, 81, 525-531. http://dx.doi.org/10.1037/0021-9010.81.5.525

Ward, T. B. (2004). Cognition, creativity and entrepreneurship. Journal of Business Venturing, 19, 173-188. 
http://dx.doi.org/10.1016/S0883-9026(03)00005-3

Watson, D., \& Clark, L. A. (1994). The PANAS-X: Manual for the positive and negative affect schedule-expanded form. University of Iowa, Iowa City.

Williams, L. J., \& Anderson, S. E. (1991). Job satisfaction and organizational commitment as predictors of organizational citizenship and in-role behavior. Journal of Management, 17, 601-617. http://dx.doi.org/10.1177/014920639101700305 